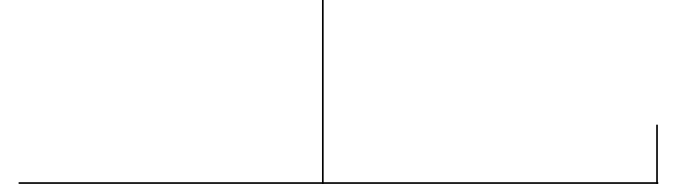

Rev. Latinoam. Psicopat. Fund., VI, 4, 177-181

Saber, verdade e gozo. Leituras de O Seminário 17 de Jacques Lacan Doris Rinaldi e Marco Antônio Coutinho Jorge (Org.)

Rio de Janeiro: Rios Ambiciosos, 2002

\title{
E a história continua...
}

\section{Vera Lúcia Colucci}

Saber, verdade e gozo é o título desta coletânea de artigos que, como o próprio subtítulo diz, trata de leituras realizadas a partir de O seminário 17: o avesso da psicanálise, de Jacques Lacan. São leituras desenvolvidas em uma das disciplinas do curso de mestrado em Pesquisa e Clínica em Psicanálise, do Instituto de Psicologia da UERJ, como nos esclarece Doris Rinaldi, na Apresentação do livro. Nessa coletânea há também contribuições de outros professores e alunos do referido Programa de PósGraduação. O espírito do livro, conforme Rinaldi, é refletir o trabalho que ali se realiza, cujo intuito é privilegiar, no ensino da psicanálise, a interseção entre teoria, clínica e pesquisa.

Antes de qualquer comentário, há que se festejar mais esta publicação, efeito da recente produção escrita da psicanálise originada na universidade, a qual tem gerado trabalhos e reflexões inovadores que se apresentam sob a forma de artigos, teses e dissertações. Às vezes livro, às vezes revista, elas mostram o esforço de psicanalistas brasileiros na apropriação dos conceitos, na maior parte gerados em outros tempos e espaços. Ao expor os próprios caminhos de articulação, partilham e com isso criam e engrossam o caldo de cultura donde podem resultar efetivas contribuições para a psicanálise no Brasil.

O apelo irresistível deste livro é, para mim, pensá-lo nele mesmo, como fato recente de nossa história, e por isso recorro a outra publicação desse empreendedor grupo de psicanalistas: Clínica e pesquisa em psicanálise, produzido em 2000, no mesmo Instituto, e organizado por 
R E V I S T A

Sônia Alberti e Luciano Elia, ambos autores presentes no livro objeto desta resenha. Logo na Apresentação daquele, Sônia Alberti faz um breve e interessante histórico da criação do referido curso de mestrado, acompanhado de importantes indagações enfrentadas acerca das relações: psicanálise e universidade, produção teóricoclínica e formação de analista. Uma vez criado o curso de mestrado, nos conta Alberti, setenta candidatos logo se inscreveram para a primeira seleção às 12 vagas destinadas à primeira turma. Anos depois, em 2000, data daquele primeiro livro, os primeiros mestrandos já apresentavam seus trabalhos, e mais inscrições para o mestrado continuavam a acontecer.

Sinal de que preenchera uma expectativa, mas qual? Por que tem sido a psicanálise a noiva mais desejada nas universidades e cursos de especialização no Brasil, quando já tivemos a era do domínio do comportamentalismo nas faculdades de psicologia? O que isso tem a ver com o boom da psicanálise na América Latina? Vem aí o cognitivismo? São perguntas que longe de pretender examiná-las nesse espaço, são provocadas por essa importante publicação.

A ampliação do universo dos interessados e praticantes da psicanálise, assim como sua difusão, tem forçado a ampliação de novos espaços de oferta desse saber. $\mathrm{O}$ vertiginoso aumento das faculdades na área $p s i$ veio produzir grande demanda pela continuação de cursos pós-faculdade, que por sua vez criou mais e mais circulação do discurso psicanalítico, realimentando, assim, a própria demanda. Pode-se dizer que a presença da psicanálise na universidade acontece pari-passu com a ampliação do mercado consumidor universitário e também com a diversificação dos lugares e modos de instauração do dispositivo psicanalítico que rompem com o setting tradicional do consultório privado, por exemplo, junto à saúde e educação. Essas passagens trazem indagações e ajustes.

A história de relação da psicanálise com a universidade foi conturbada, bem sabemos, já com o próprio Freud, que, dialeticamente, atribuiu ao seu isolamento dos meios acadêmicos o ganho de independência e autonomia na invenção de seus conceitos, pois viu-se livre do controle do discurso científico e universitário da época.

A relação do saber psicanalítico com a universidade sempre foi cercada por certo incômodo, quando não de franca hostilidade, seja porque ela expande fronteiras e rompe espaços restritivos e tradicionais de circulação, seja porque 0 discurso da psicanálise estranha o modo de produção de saber exercido na universidade. Muitas vezes as resistências vinham das próprias Sociedades de Psicanálise vinculadas à Sociedade Internacional. Essas sociedades foram as primeiras instituições de produção e divulgação do saber psicanalítico, elas mesmas erguidas a partir da matriz inglesa, principal sede e centro irradiador de suas similares a partir do exílio de Freud na Inglaterra, em 1938. Por longo tempo as sociedades de psicanálise resistiram ao ensino da psicanálise fora de seus muros, quer fossem em instituições autônomas, quer nas universidades, até 
mesmo proibindo seus membros de participarem dessas iniciativas. Ainda assim, o saber psicanalítico tem vazado fronteiras, ora numa proposta de grupos organizados, fora dos institutos ligados às sociedades, ora por professores isolados, especialmente nas faculdades de psicologia.

O mesmo processo acontece no plano do dispositivo terapêutico, quando o saber técnico se expõe mais à experiência do exercício da psicanálise, à clínica, do que às prescrições formais tradicionais. E, com isso, a teoria se enriquece.

Como nos informa Roudinesco em História da psicanálise na França (1988), a presença da psicanálise nas universidades francesas tomou força a partir de alguns acontecimentos, entre os quais sua democratização, o que fez aumentar em muito o contingente de alunos com formação escolar menos elitista. As conferências realizadas por Lacan, além de muito concorridas, tiveram grande importância, pois conquistaram os principais intelectuais da época, atraídos especialmente por sua inventividade nos usos dos conceitos da lingüística, da antropologia, da filosofia, matemática e topologia. Com a democratização, seu público mudou bastante, conforme nos conta Roudinesco (1988), e as repercussões do movimento de maio de 1968 tiveram, também, sua incidência. Devemos lembrar que O seminário, livro 17, data de 1969.

Como ensinar do que não está para o dizer? Como falar a outros que querem saber de um saber que não se sabe? A saída teórica encontrada por Lacan, sustentada pelo aforismo de Wittgenstein (1889-1951) de que "o que não se pode falar, deve-se calar” (Wittgenstein, 1991) é buscar letras e relações topológicas para escrever as relações do real que se produzem na experiência psicanalítica. O discurso, estrutura sem palavras, é representado por relações que são a unidade mínima do laço social.

Podemos não apenas aproximar a formulação de Lacan sobre os quatro discursos dos acontecimentos incandescentes de 1968, já que é aí que discute o discurso do Mestre e o universitário, e das grandes inquietações intelectuais de sua época, mas com Roudinesco devemos também apreciar como Lacan estava igualmente atando os fios deixados por Wittgenstein (1991), especialmente quando este vai dizer que "uma proposição não traz em si o todo da linguagem. Esta procede através de pequenos segmentos, que são diferentes, múltiplos e, parcelados. A única semelhança que tais segmentos possuem entre si é 'um certo ar de família', constituindo cada um deles um 'jogo de linguagem'. Um jogo de linguagem só pode ser definido pela comparação entre os traços semelhantes e definitivos de uma série de jogos. Com essa colocação do problema, Wittgenstein aproxima-se muito do estruturalismo de Saussure” (idem, 1991). E aqui reencontramos o autor lingüista que permitiu a Lacan reler Freud.

O livro que motiva esta resenha, contou com apoio da Capes e do Instituto de Psicologia da URFJ. Ele está dividido em sessões, e de cada uma delas constam elaborações que exploram o próprio Seminário 17. Além da interessante 
R E V I S

apresentação feita por Doris Rinaldi, em que situa o surgimento da idéia do livro a partir de suas aulas na disciplina “Tópicos especiais em psicanálise”, também situa o tema tratado em $O$ Seminário, livro 17, e comenta a trabalho de cada um dos autores, divididos em Partes: II - Psicanálise e universidade; III Psicanálise e ciência; IV - O lugar do Pai; V-Saber e verdade; - O campo do gozo e VII - Psicose e laço social. Não pretendendo comentar cada artigo em separado, ressalto, porém, a forte impressão deixada pela leitura: qual seja, a de que aqui se faz psicanálise... É visível o compromisso em fazer trabalhar conceitos veiculados em $O$ Seminário, livro 17. Os diferentes problemas eleitos pelos diversos autores dos artigos são mencionados já em seus títulos e articulam a clínica, a teoria e a pesquisa em psicanálise, em que figuram alguns exemplos apontados aqui ao acaso: desejo do psicanalista no campo da saúde mental, “impotência da verdade" e homossexualidade, lugar do sujeito na escola, processo de reabilitação, debilidade mental, depressão, desejo na velhice, autismo e psicose infantil, e outras inquietações advindas da prática, como a questão da lei num grupo operativo em Manicômio Judiciário, e outros de cunho mais teórico, como os apontamentos da relação discurso e liame social. Abstenho-me de comentar todos, nem sequer escolho um só, no impasse de evitar repetir a escolha de Sofia. Deixei-me antes capturar, como ressaltei logo de início, pela presença mesma da publicação desse conjunto de importantes trabalhos advindos desse novo espaço que é o da pós-graduação. Fico em dívida, porém, com o respeito que cada um desses autores deixaram em mim, recomendando que o leitor vá até os textos e retire deles o ensinamento. O compromisso dos autores é o da apropriação do texto de Lacan, reconhecidamente rico de possibilidades para gerar significações. E é também com a colocação em circulação de seus trabalhos, com o que obtêm sucesso. Note-se que a própria repetição dos esquemas e descrições dos matemas dos discursos formulados por Lacan - em quase todos os artigos do livro que resenho se insiste nos matemas - ao contrário de enfadar o leitor, contribui para retomar a cada tanto as posições e os giros de lugares e funções nos discursos, voltando e voltando sempre, para partir em direção a outros caminhos, em direção aos problemas definidos por seus respectivos autores.

Do livro, ressalto ainda o cuidado com a edição, especialmente quando traz na contracapa, na borda da orelha, como um marcador de livro, uma aba destacável, algo como uma régua, daquelas que continham as tabuadas e que tanto nos socorriam no momento de resolver problemas de aritmética. Nessa divertida e criativa aba se inscrevem as fórmulas dos discursos e sua nomenclatura, de tal modo que ao ser destacada da orelha do livro ela pode caminhar conosco pelas páginas afora, como presença impressa dos matemas, sempre prontos a nos escapar ao procurarmos apreendê-los. Reparo, todavia, o ainda escasso leque de referência de autores nacionais no decorrer dos artigos, pois eles já existem. Faz parte da apropriação dos conceitos entrar nos debates 
existentes, e se isso é feito a cada um, ainda assim o tal do levantamento bibliográfico ganha sentido nada ritualístico. Mas o fato de ser reflexo de produções realizadas no correr de um curso, absolve totalmente essa ausência. De fato, alguns artigos têm o caráter de funcionar como faróis que iluminam o caminho pelos textos do Lacan, pois partilham as articulações que seus autores fizeram, os recursos de que se serviram para ler O Seminário, livro 17. Outros enfrentam questões colocadas por sua prática.

A veiculação da psicanálise no espaço universitário, sem dúvida força sua aculturação, fazendo-nos assumir palavras novas. Isso exige que as desgarremos de suas incrustrações tradicionais, o que, com muito trabalho, impõe o cuidado de revesti-las de novas significações, em que ainda possamos reconhecer nossos traços de identidade. A palavra pesquisa é o exemplo mais transparente disso, pois fortemente associada às práticas investigativas baseadas na coleta e controle de dados, deve passar agora, no âmbito das pesquisas em psicanálise, por toda uma refundação que permita erguer sua especificidade nesse novo campo. Estas condições tornam altamente desafiante estar nesse espaço múltiplo, a universidade, saber-nos navegando em mar aberto, expostos ao questionamento, vindos de outros territórios, de outras línguas, sujeitos às quatro críticas, na melhor das hipóteses, dos bem informados e interessados na psicanálise, e também dos que a estranham, mas não lhe são hostis. Podemos nos perguntar, assim, que diferenças são produzidas se a inserção da psicanálise se faz a partir de um centro de psicologia, de medicina, lingüística ou filosofia? Que efeitos diferentes teremos nesses diálogos que se impõem, que nos empurram para esse exaustivo trabalho de descarnar conceitos para de novo retomá-los, quase obrigados a buscar um novo jeito de bem dizê-los? Não é difícil esperarmos daí uma psicanálise robustecida para enfrentar os problemas da atualidade. Mas isso leva tempo. Encontro aí o importante papel desse livro e congêneres.

\section{Referências}

Alberti, S. e Elia, L. (Org.). Clínica e pesquisa em psicanálise. Rio de Janeiro: Rios Ambiciosos, 2000.

LaCAN, J. (1969-1970). O seminário. Livro 17. O avesso da psicanálise. Rio de Janeiro: Jorge Zahar, 1992.

Roudinesco, E. História da psicanálise na França - A batalha dos cem anos. 1925-1985. Rio de Janeiro: Jorge Zahar, 1988. v.2.

Wittgenstein. Vida e obra. In: Os Pensadores. São Paulo: Nova Cultural, 1991. 